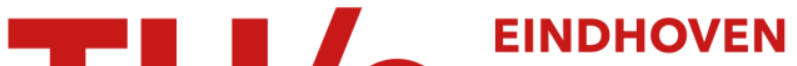 UNIVERSITY OF TECHNOLOGY
}

\section{Effect of Lateral Constraint on the Mechanical Properties of a Closed-Cell Al Foam: I. Experiments}

\section{Citation for published version (APA):}

Murthy Kolluri, N. V. V. R., Karthikeyan, S., \& Ramamurty, U. (2007). Effect of Lateral Constraint on the Mechanical Properties of a Closed-Cell Al Foam: I. Experiments. Metallurgical and Materials Transactions A: Physical Metallurgy and Materials Science, 38(9), 2006-2013. https://doi.org/10.1007/s11661-007-9245-z

DOI:

10.1007/s11661-007-9245-z

Document status and date:

Published: 01/01/2007

\section{Document Version:}

Publisher's PDF, also known as Version of Record (includes final page, issue and volume numbers)

\section{Please check the document version of this publication:}

- A submitted manuscript is the version of the article upon submission and before peer-review. There can be important differences between the submitted version and the official published version of record. People interested in the research are advised to contact the author for the final version of the publication, or visit the $\mathrm{DOI}$ to the publisher's website.

- The final author version and the galley proof are versions of the publication after peer review.

- The final published version features the final layout of the paper including the volume, issue and page numbers.

Link to publication

\section{General rights}

Copyright and moral rights for the publications made accessible in the public portal are retained by the authors and/or other copyright owners and it is a condition of accessing publications that users recognise and abide by the legal requirements associated with these rights.

- Users may download and print one copy of any publication from the public portal for the purpose of private study or research.

- You may not further distribute the material or use it for any profit-making activity or commercial gain

- You may freely distribute the URL identifying the publication in the public portal.

If the publication is distributed under the terms of Article 25fa of the Dutch Copyright Act, indicated by the "Taverne" license above, please follow below link for the End User Agreement:

www.tue.nl/taverne

Take down policy

If you believe that this document breaches copyright please contact us at:

openaccess@tue.nl

providing details and we will investigate your claim. 


\title{
Effect of Lateral Constraint on the Mechanical Properties of a Closed-Cell Al Foam: I. Experiments
}

\author{
M. KOLLURI, S. KARTHIKEYAN, and U. RAMAMURTY \\ An experimental investigation into the effect of lateral constraint on mechanical properties of a \\ closed-cell Al foam, Alporas, was conducted. Results show that while the initial plastic strength \\ of the foam is unaffected, the constraint induces significant strain hardening as plastic defor- \\ mation progresses. The strain hardening is also sensitive to the relative density of the foam, \\ increasing with density. Further, the constraint is seen to reduce the densification strain and, at \\ the same time, to enhance the energy absorbed per unit volume of the deformed foam. Impli- \\ cations of these changes to the deformation characteristics of foams, in terms of energy \\ absorption efficiency and plastic strain accumulation during fatigue, are demonstrated and \\ discussed. A companion article gives the details of the constitutive modeling undertaken to \\ rationalize the observed strain hardening under constraint.
}

DOI: $10.1007 / \mathrm{s} 11661-007-9245-\mathrm{z}$

(C) The Minerals, Metals \& Materials Society and ASM International 2007

\section{INTRODUCTION}

THE mechanical behavior of metal foams has been extensively investigated in the recent past. ${ }^{[1-6]}$ The plastic response of closed-cell metal foams is largely determined by collective cell collapse. ${ }^{[1]}$ Progressive cell band collapse, from one band to another, results in a long plateau in the compressive stress-strain curve after an initial elastic regime. This phenomenon continues until all the cells have collapsed, which results in a steep rise in the stress with further strain. The strain at which this transition occurs is referred to as the densification strain, $\varepsilon_{d}$. This large plastic plateau up to a $\varepsilon_{d}$ of $\sim 60$ to 70 pct in aluminum foams has two important practical consequences. First, it allows for a large amount of energy absorption, making $\mathrm{Al}$ foams attractive candidates for impact energy absorbing applications. Second, by suitable design in blast amelioration systems, it is possible to limit the stress experienced by the protected components to that of plateau stress.

In the unconstrained uniaxial compression tests, the collapse of the first cell band often leads to the shear displacement of one part of the specimen with respect to the other, resulting in the loss of uniaxiality. This becomes an issue particularly at large strain. A lateral constraint is expected to prevent such a shear displacement and could lead to strain hardening. However, this possibility has not been given due consideration yet, as the plastic Poisson ratio of metal foams is presumed to be equal to zero that would result in insignificant transverse strains during uniaxial compression.

M. KOLLURI, formerly Master of Engineering Student, Department of Materials Engineering, Indian Institute of Science, Bangalore 560012 , India, is Doctoral Researcher, Mechanical Engineering Department, Netherlands Institute for Metals Research, Eindhoven University of Technology, 5600 MB Eindhoven, The Netherlands. S. KARTHIKEYAN, Assistant Professor, and U. RAMAMURTY, Associate Professor, are with the Department of Materials Engineering, Indian Institute of Science. Contact e-mail: ramu@materials.iisc.ernet.in

Manuscript submitted November 20, 2006.

Article published online July 18, 2007.
In most practical applications of metal foam containing parts, there will be a reasonably thick face sheet covering the foam, which will act as a barrier for unconstrained shear displacements. A similar scenario exists for the foam filled columns and boxes, which are potential candidates for sacrificial energy absorbers under low velocity impact as well as in blast amelioration applications. Here, the design is such that the protected part sees the plateau stress at the maximum. If there is any strain hardening in the foam due to the constrained deformation, the protected part may experience higher stress. The fatigue response of metal foams is also likely to be affected pronouncedly. Accurate description of the constitutive response of the metal foam under constraint is essential for designing foamfilled components. Despite its significant implications to the design of such components, no studies have been conducted to examine the effect of constraint on mechanical properties of metal foams, and this is the objective of the present study.

In this article, we report experimental results on the mechanical properties of a closed-cell $\mathrm{Al}$ foam tested in quasi-static uniaxial compression with and without constraint. Experimental results indicate that the constraint induces a positive slope to the stress-strain curve in the plastic regime that is not seen without constraint. The reasons for the observed hardening and its implications to energy absorption during impact and on fatigue properties are discussed. Analytical models that rationalize the observed hardening behavior are presented in a companion article. ${ }^{[7]}$

\section{MATERIAL AND EXPERIMENTS}

\section{A. Material}

A closed-cell aluminum foam, manufactured by Shinko Wire Co. (Osaka, Japan), with the trade name 
Alporas was used for the present study. Manufacturing of this material involves mixing a solid foaming agent ( 1 to 3 pet $\mathrm{TiH}_{2}$ powder) into molten aluminum at 680 ${ }^{\circ} \mathrm{C}$, where the hydride decomposes releasing hydrogen gas, which helps in the foaming of molten Al. Calcium is added to the melt to increase the viscosity of the melt and hence stabilize the foam. Processing details and relevant properties of this foam can be found elsewhere. ${ }^{[3,8-10]}$ Extensive characterization of Alporas, carried out by Simone and Gibson, ${ }^{[11]}$ shows that it has homogeneous cellular structure. Minimal ellipticity was observed, indicating that the foam is highly isotropic. In addition, the wall thickness of this foam was found to be invariant with respect to the spatial position. The average cell size in this foam is $\sim 3.8 \mathrm{~mm}$.

Several $500 \times 500 \mathrm{~mm}^{2}$ Alporas plates with $100-\mathrm{mm}$ thickness were procured. From these plates, parallelepiped compression testing specimens of $50 \times 50 \mathrm{~mm}^{2}$ cross section and 25-, 50-, 75-, and 100-mm heights were prepared by electrodischarge machining (EDM). This large cross section was chosen to accommodate and sample a large number of cells and to average out possible size effects. Care was exercised so that all the tests were conducted with the loading direction perpendicular to the as-received plate. This was done in order to eliminate any mechanical anisotropy in properties which may complicate interpretation of the results. ${ }^{[1]}$

The relative density, $\rho^{*}$ (given by the ratio of density of the foam, $\rho$, to the density of constituent solid, $\rho_{s}$ ), exerts a major influence on the mechanical properties of foams. ${ }^{[1,2,11,12]}$ With this in mind, $\rho^{*}$ of each individual sample was measured (through weight and volume measurements for all machined samples) and kept track-of throughout the experimental campaign. The $\rho^{*}$ distribution of the samples tested is plotted in Figure 1, which shows that it varies between 0.07 to 0.11 , with a mean value of 0.091 and a standard deviation of 0.012 .

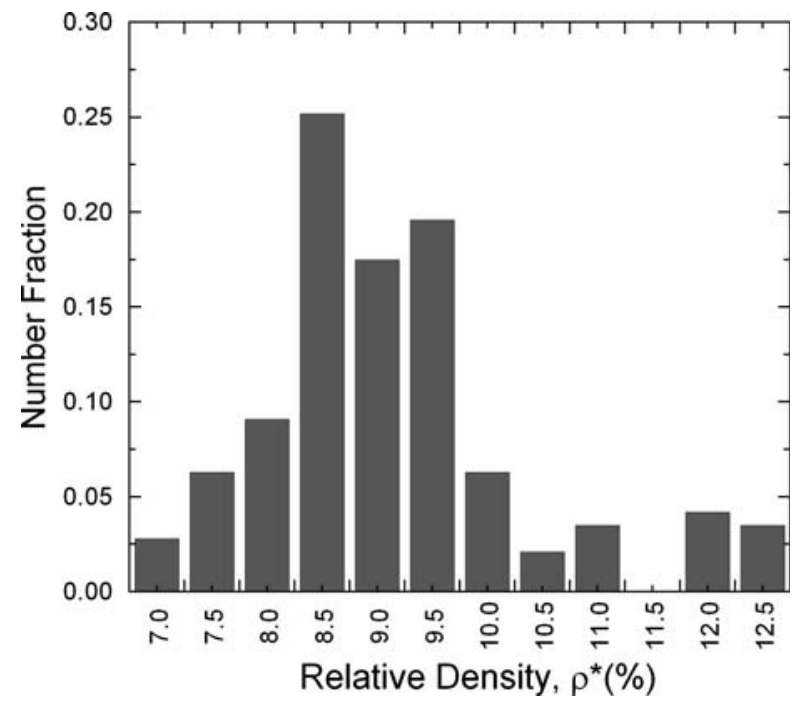

Fig. 1-Histogram of the relative density, $\rho^{*}$, distribution among the tested Alporas samples.

\section{B. Experiments}

Uniaxial compression tests were conducted in an Instron servohydraulic universal testing machine under displacement control. Because the mechanical properties of Alporas are strain-rate sensitive, ${ }^{[13,14]}$ all tests were conducted at a single crosshead displacement rate of $0.1 \mathrm{~mm} / \mathrm{s}$. A die-steel sleeve with a slightly larger inner cross section (than the $50 \times 50 \mathrm{~mm}^{2}$ of the specimens) and $118-\mathrm{mm}$ depth was fabricated and used as the lateral constraint during compression testing. Specimens were placed in this sleeve (Figure 2) and a solid aluminum block of $50 \times 50 \mathrm{~mm}^{2}$ was placed on the foam specimen. This entire setup was placed between parallel rigid platens of the universal testing machine and compression tests were performed. For the unconstrained tests, the Alporas samples were simply placed between the platens and tested. In all cases, the crosshead displacement was used for measuring the strain during deformation. This is mainly for two reasons: it is not possible to fix an extensometer to the sample in the case of tests with constraint. In the case of the unconstrained specimens, mounting of an extensometer to the foam material is difficult because of the large cell size and thin cell walls. Because the properties of Alporas, despite being the best commercially available foam, exhibit a relatively large degree of variability, ${ }^{[15]}$ a number of tests was performed in order to obtain statistically significant information.

In order to examine if there are any differences in micromechanisms of deformation, select compression tests were interrupted for a few samples (after a strain of $\sim 26$ pct) and the samples were sectioned using EDM. Subsequently, they were polished, sprayed with a black paint (in order to get good contrast), and gently polished again to reveal the cellular structure.

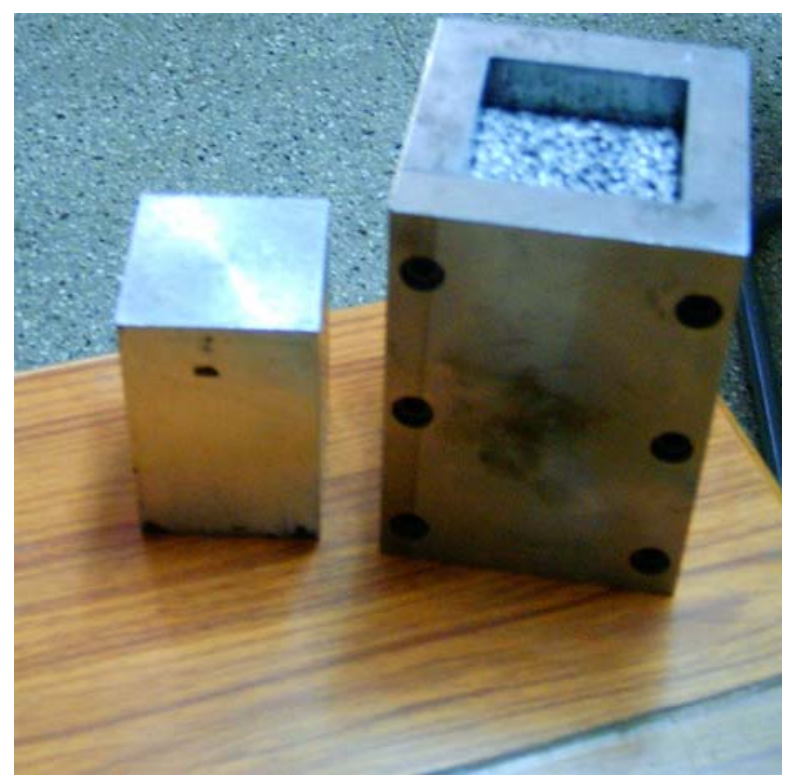

Fig. 2-Photograph of the steel sleeve (right) used for proving the lateral constraint and solid $\mathrm{Al}$ block employed for loading the $\mathrm{Al}$ foam. 


\section{RESULTS AND DISCUSSION}

\section{A. Plastic Strength}

The typical stress-strain response of Alporas with and without constraint (with similar $\rho^{*}$ of $\sim 0.9$ ) is shown in Figure 3(a). Both show an initial elastic regime that is followed by a long plastic regime, which gets truncated by the onset of densification (marked by a steep rise in the stress with further strain). While the unconstrained foam's plastic stress-strain curve is nominally flat, as widely reported in the literature,$^{[1,15,16]}$ the constrained sample shows strain hardening. The influence of $\rho^{*}$ on the strain hardening behavior is illustrated in Fig-

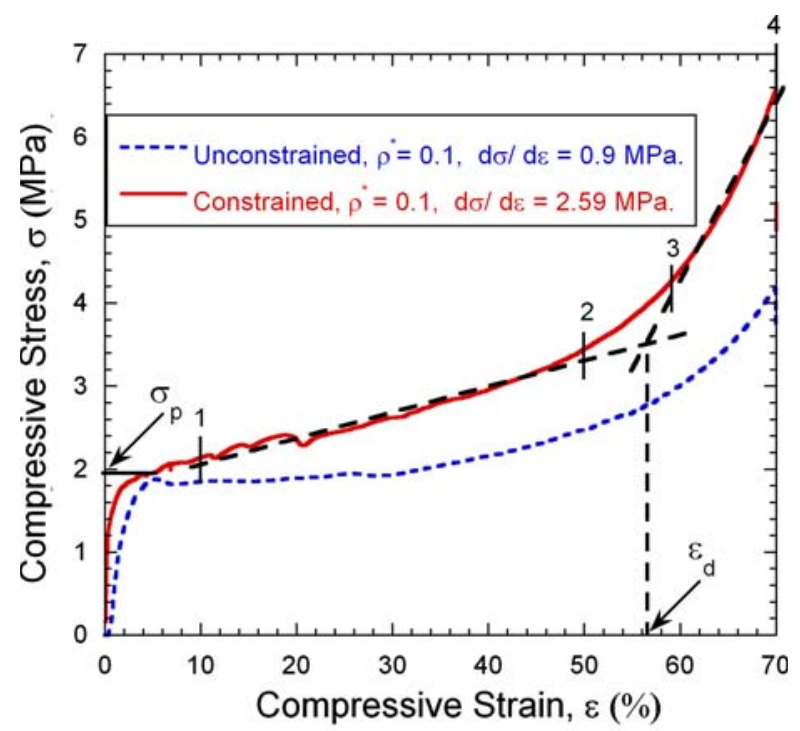

(a)

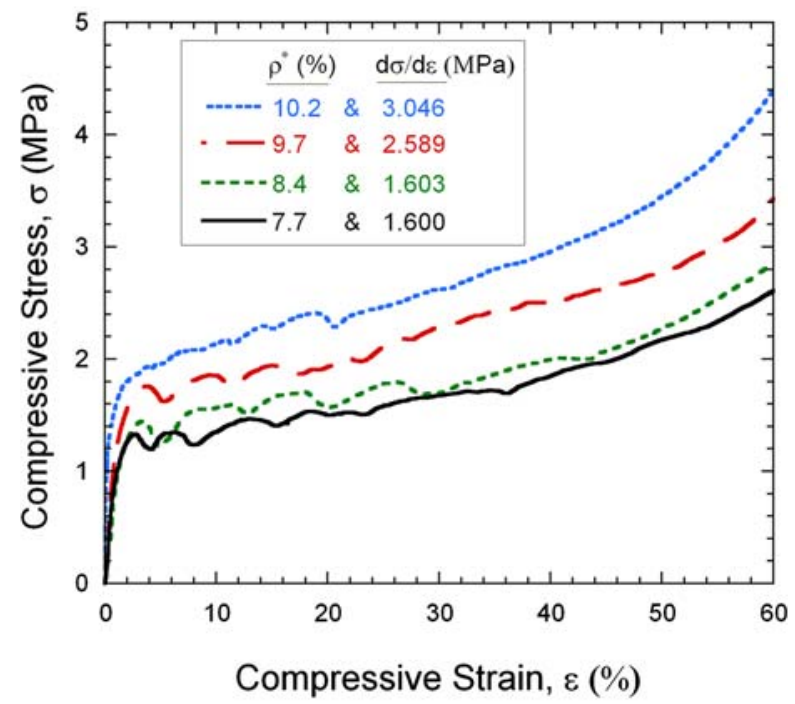

(b)

Fig. 3-(a) Typical stress, $\sigma$, -strain, $\varepsilon$, response of the ALPORAS foam with and without constraint in uniaxial compression. Procedure employed for extracting the densification strain, $\varepsilon_{d}$, is also shown. (b) $\sigma-\varepsilon$ responses obtained on specimens with different relative density, $\rho^{*}$, showing that the nominal strain-hardening rate, $d \sigma / d \varepsilon$, is sensitive to $\rho^{*}$. ure 3(b), wherein the stress-strain responses of constrained specimens with different $\rho^{*}$ are plotted. It is seen that the strain hardening is also sensitive to $\rho^{*}$, increasing with $\rho^{*}$.

The variation of the plastic strength, $\sigma_{p}$, extracted from the compression stress-strain curves with $\rho^{*}$ is plotted in Figure 4(a). Here, the first peak value in the plastic part of the stress-strain curve was chosen as the $\sigma_{p}$. From Figure 4(a), it is seen that the $\sigma_{p}$ is independent of the constraint, as it affects only the latter part of plastic stress-strain response. Various scaling relations, which connect mechanical properties of the foams to the respective properties of their parent metal through the relative density of the foam, have been derived in the literature by considering the micromechanics of deformation. ${ }^{[1,17,18]}$ By considering the bending of the cell edges and stretching of the cell faces and assuming that they (cell edges and faces) have uniform thickness, Gibson and Ashby ${ }^{[1]}$ have derived the following relation between $\sigma_{p}$ and $\rho^{*}$ for closed-cell foams:

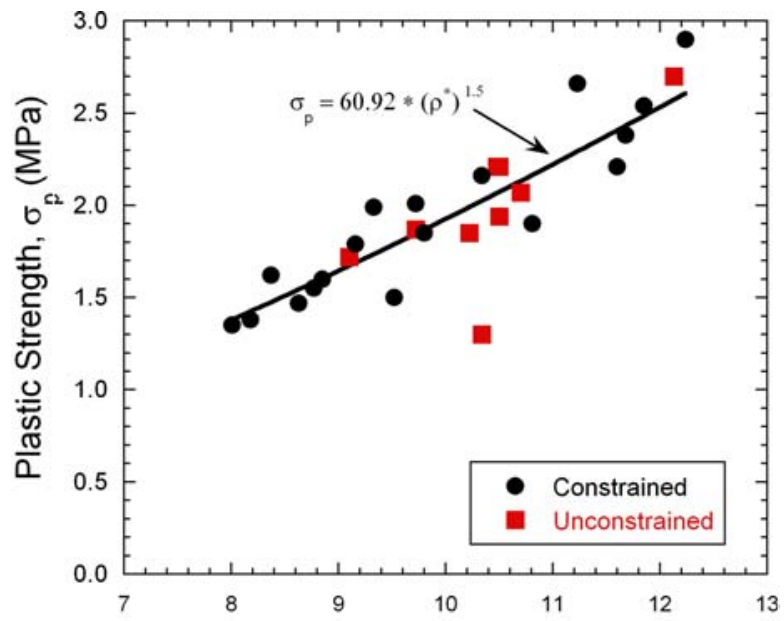

(a)

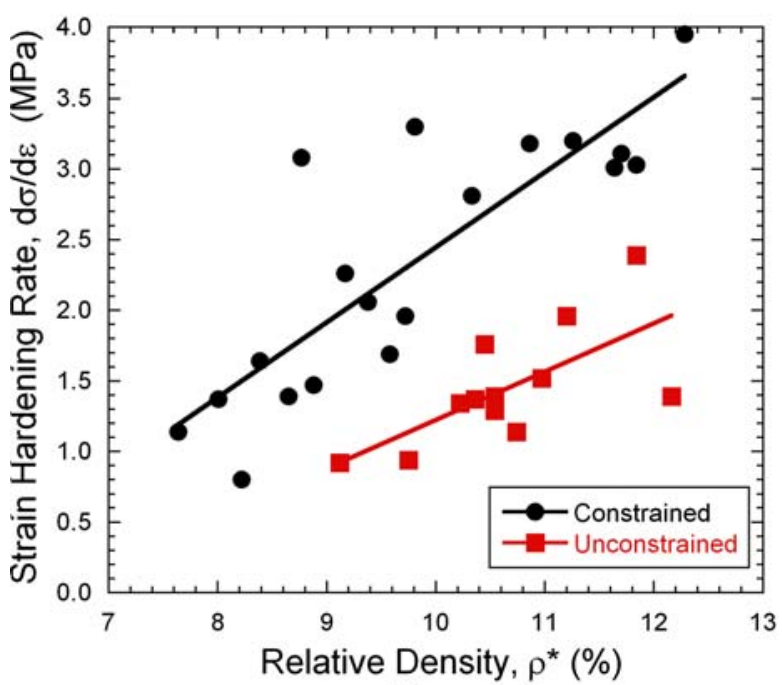

(b)

Fig. 4-Variation of $(a)$ the plastic strength, $\sigma_{p}$, and $(b)$ the strainhardening rate, $d \sigma / d \varepsilon$, with the relative density, $\rho^{*}$, of the Alporas foam tested with and without constraint. 


$$
\frac{\sigma_{p}}{\sigma_{m, y}}=0.3 \phi \rho *^{2}+(1-\phi) \rho *
$$

where $\phi$ is the volume fraction of solid contained in the cell edges, and $\sigma_{m, y}$ is the yield strength of the parent material. Finite element simulations by Simone and Gibson ${ }^{[17]}$ on a tetrakaidecahedral closed cell with flat faces (Kelvin foam) show that

$$
\frac{\sigma_{p}}{\sigma_{m, y}}=0.3346 \rho *^{2}+0.4445 \rho *
$$

For $\rho^{*}<20$ pct, the first term in Eq. [2] becomes negligible, implying that the stretching of the cell faces is the deformation mode of significance. ${ }^{[17]}$

Note that these predictions give the upper bound for metallic foams. Examination of the microstructure of the Alporas shows the presence of many types of defects that can be classified into either periodic defects, such as plateau border and wiggles, or random defects, such as missing cell walls, poly-dispersity in cell sizes, and cell wall misalignment. Even for a foam with a nominally constant $\rho^{*}$, the presence of these defects can affect the mechanical behavior in a significant manner. Cell wall curvature and corrugations are the important defects among these, whose influence on the modulus and yield strength have been modeled by Simone and Gibson ${ }^{[19]}$ using finite element simulations. For periodic tetrakaidecahedra cells, it is found that there could be as much as a 70 pct drop in mechanical properties due to the presence of defects in the microstructure. For closed-cell foams, however, the distribution of the solid material between the cell faces and plateau borders along the edges or thickening of the nodes were found to have little effect on the elastic modulus of the foam because the primary mechanism of deformation in closed-cell foams is the in-plane stretching of cell faces. ${ }^{[1,17]}$ Sugimura et al. ${ }^{[3]}$ have investigated the microstructural features of the Alporas and found that cell edges and faces are not uniform and edges are much thicker than cell faces, so that cell faces have a minimal effect on elastic modulus and plastic strength. Extensive work on Alporas and other closed-cell metallic foams with different relative densities has shown that $\sigma_{p}$ variation with $\rho^{*}$ is better described by

$$
\frac{\sigma_{p}}{\sigma_{m, y}}=0.3(\rho *)^{1.5}
$$

an equation that is derived for open cell foams, inferring that plastic buckling of the cell walls dictate the plastic strength of the foam. ${ }^{[15,20]}$ A least-squares fit of Eq. [3] through the $\sigma_{p}$ vs $\rho^{*}$ data gives $\sigma_{m, y}=203 \pm$ 4.2 $\mathrm{MPa}$, which is slightly higher than the $172 \mathrm{MPa}$ by Simone and Gibson ${ }^{[11]}$ for Alporas inferred from the Vickers microhardness measurements.

\section{B. Strain Hardening}

As mentioned earlier, the plastic stress-strain responses of the unconstrained and constrained samples diverge with increasing plastic strain, with the specimens tested with lateral constraint exhibiting considerable strain hardening. To quantify this, the strain-hardening rate, $d \sigma / d \varepsilon$, was defined as the slope of the stress-strain curve between strains 0.1 and 0.5 . Here, linear hardening was assumed as a first-order approximation, although the flow stress for both constrained and unconstrained cases does exhibit some degree of accelerated strain hardening. This definition of the strain-hardening rate is simply a device for comparison. The dependence of $d \sigma /$ $d \varepsilon$ on $\rho^{*}$ for the constrained and unconstrained cases is shown in Figure 4(b). It is clear that for the same $\rho^{*}$, foam specimens tested under lateral constraint exhibit a higher strain hardening rate, though it is worth mentioning that even samples without constraint show a measurable $d \sigma / d \varepsilon$. It is also observed that while denser foams exhibited greater hardening in both cases (as much as 3 to $3.5 \mathrm{MPa}$, which is higher than the highest $\sigma_{p}$ values seen in Figure 4), the slope of the linear fit for $d \sigma / d \varepsilon$ vs $\rho^{*}$ data is higher (53.22 vs $\left.34.32 \mathrm{MPa}\right)$ for samples tested with constraint than for specimens tested without constraint.

The observed higher hardening rates in the constrained specimens could be due to two reasons. The application of the constraint changes the stress state from uniaxial to triaxial and this is expected to cause strain hardening. In this context, it is worth noting that enhanced strain hardening under multiaxial loading of foams has been reported by several authors. ${ }^{[21,22]}$ Deshpande and Fleck ${ }^{[21]}$ note that the increase in strain hardening during hydrostatic compression is greater in higher density foams. On the basis of these experimental results, they have developed a phenomenological yield surface model. On similar lines, Miller et al. ${ }^{[23]}$ and Zhang et al. ${ }^{[24]}$ developed constitutive models that incorporate the plastic Poisson's ratio and some hardening law. The second source of hardening is extrinsic and is due to friction between the die steel sleeve and foam surface. In a companion article, we model the effect of combined intrinsic and extrinsic hardening on the constrained deformation of the closed-cell foam and show that the observed hardening in the constrained samples is due to this modification in stress state as well as the friction.

In order to examine if the deformation mechanisms under constraint are different from the propagation of collective cell band collapse from one band to another, tests were interrupted and sectioned foams were examined. Figure 5(a) shows the midsection of a specimen that was tested in constraint to a total strain of $\sim 26$ pct. Densified regions, approximately 8 to $10 \mathrm{~mm}$ in width and oriented at a $\sim 15$-deg angle to the loading direction, are seen. Typically, these bands span the entire width of the specimen. Further, the higher magnification view of the areas adjacent to the collapsed cell bands (Figure 5(b)) shows incipient collapse of bands, with buckled cell walls. Broadly, these observations are consistent with the micromechanisms of deformation reported for unconstrained metal foams by Evans and co-workers. ${ }^{[16,18,25]}$ However, some subtle differences do exist. Bastarwos et al. ${ }^{[25]}$ identified three distinct micromechanistic stages during the initial yielding of foams under compression loading. Following the first stage of linear elastic deformation, cells distort in collective fashion 


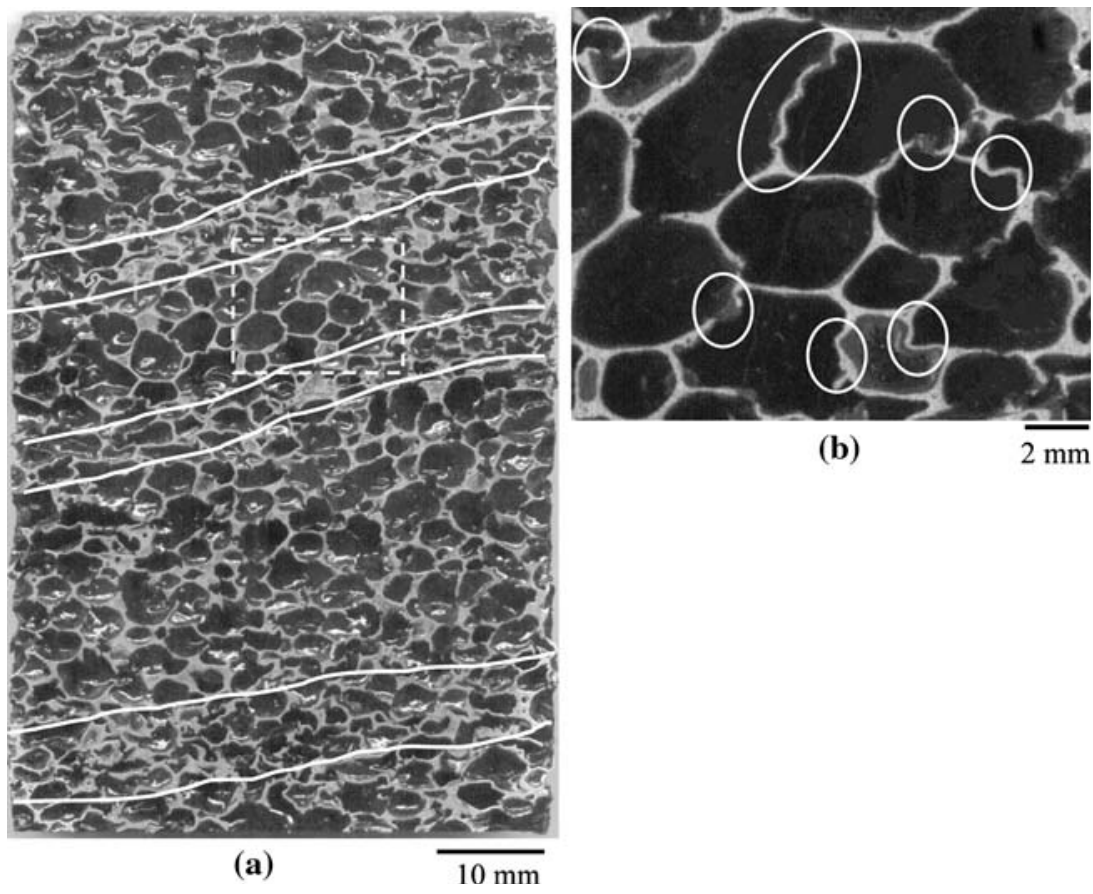

Fig. 5-(a) Low-magnification image of the midsection of an Alporas specimen that was subjected to a total strain of 30 pct. (b) Higher magnification image of the boxed region in (a) showing cell-wall buckling adjacent to a collapsed band.

along a band that is one cell diameter in width. In this second stage of deformation, plastic buckling and bending of individual membranes induces strain concentration (due to elastic distortion and rotation) in neighboring cells of comparable strengths. This leads to deformation localization in a layer of cells perpendicular to the loading axis due to stress redistribution. However, the elastic enclave contiguous to this layer of cells deactivates the band collapse in this stage. The bands formed are one cell wide, discrete, and are separated by a minimum distance of about four cell diameters ( $\sim 16 \mathrm{~mm}$ for Alporas). This characteristic length is the width of elastic enclave where the strain is accommodated before plastic collapse. These bands formed in stage 2 will collapse with further strain in stage 3, leading to maxima at an initial portion of stress-strain curve. The cross section of the deformed foam under constrained conditions shown in Figure 5(a) indicates, in contrast, that the deformed regions are much wider and inclined at an angle to the loading axes. Also, the densified regions appear to promote plastic cell collapse adjacent to them. Detailed X-ray tomographic studies are underway to examine these possibilities.

\section{Densification Strain and Energy Absorption}

The region of apparent strain hardening (for samples under constraint) or no strain hardening (for samples without constraint) is followed in both cases with a rapid increase in stress with strain. This is traditionally thought to correspond to densification ${ }^{[1]}$ and the strain at which this transition occurs is referred to as densification strain, $\varepsilon_{d}$. Because the transition from plastic collapse of the cell walls to densification occurs rather gradually, a consistent method for evaluating $\varepsilon_{d}$ from a given stress-strain curve is necessary. Here, we have used the following approach, which is illustrated in Figure 3(a). Two linear fit curves were drawn, the first one between strains 0.1 and 0.5 (between points 1 and 2 in Figure 3(a)) and the second one between strains 0.6 and 0.7 (between points 3 and 4). The intersection of these lines is taken as $\varepsilon_{d}$. Figure 6(a) shows the variation of $\varepsilon_{d}$ on $\rho^{*}$ with and without constraint. In both the cases, $\varepsilon_{d}$ decreases with an increase in $\rho^{*}$, with a similar linear dependence, which is consistent with that predicted by Gibson et al., ${ }^{[1]}$ who show that $\varepsilon_{d}$ is dictated solely by $\rho^{*}$, such that

$$
\varepsilon_{d}=A-\rho * \phi_{v}
$$

where $A$ is a constant and $\phi_{v}$, known as the densification parameter, is a measure of the relative void space retained when all the cells have collapsed (because of the cell walls jamming into each other). Gibson and Ashby ${ }^{[1]}$ show that they are equal to 1.0 and 1.4 , respectively, for an ideal foam. For nonideal foams, such as Alporas, Ashby et al..$^{[20]}$ indicate that $A=0.8$ and $\phi_{v}=1.75$ gives a better fit for experimental data. Least-square curve fits of Eq. [5], through data shown in Figure 6(a), give $A=0.80$ and $\phi_{v}=1.98$ for the unconstrained samples, consistent with the observation of Ashby et al. In the case of the constrained samples, values of $A=0.81$ and $\phi_{v}=2.18$ are obtained. The difference between $\phi_{v}$ values of constrained and unconstrained samples is related to the lower $\varepsilon_{d}$ values in the former-the higher the value of $\varepsilon_{d}$ the lower will be $\phi_{v}$ at fixed $A$ and $\rho^{*}$. As seen at a given $\rho^{*}, \varepsilon_{d}$ is marginally higher ( $\sim 3$ to 5 pct) for the unconstrained samples. Although this appears to be small, it should be noted 


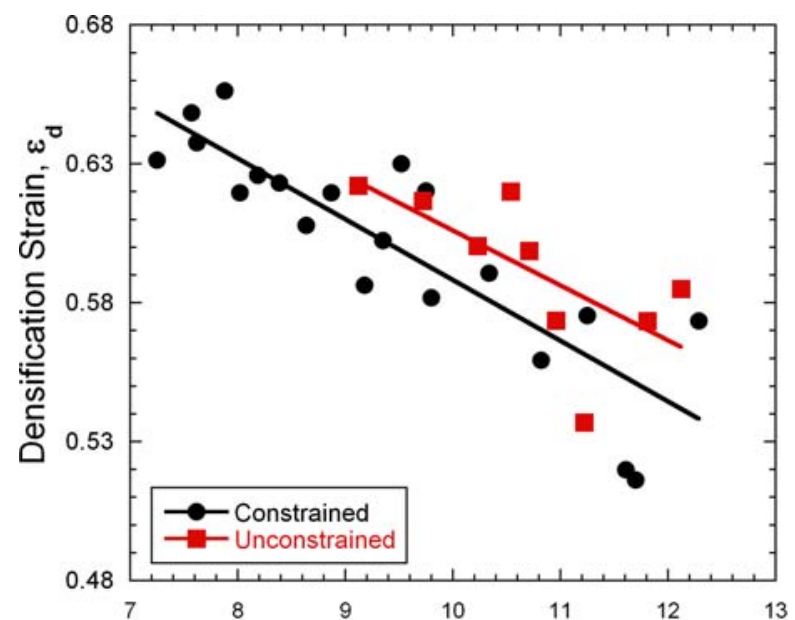

(a)

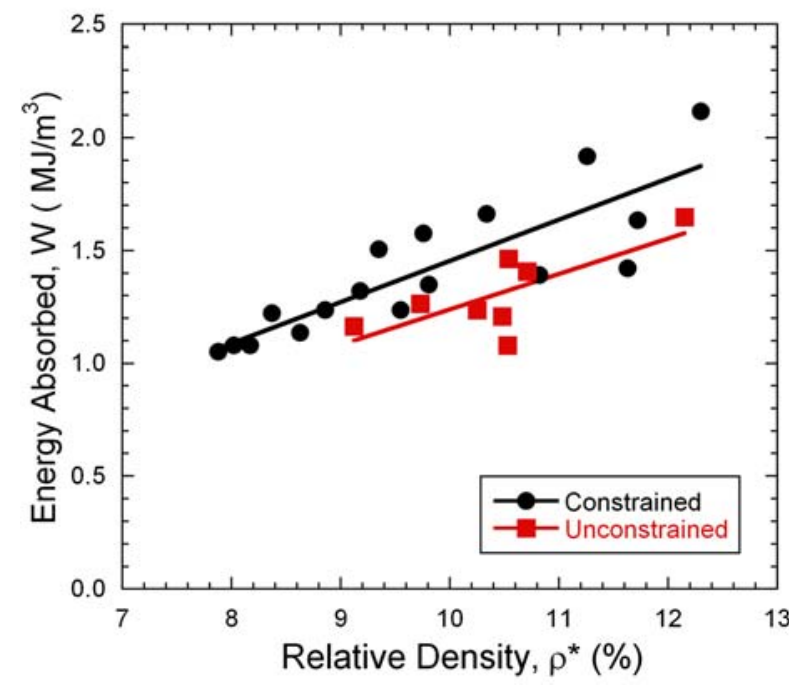

(b)

Fig. 6-Variation of $(a)$ the densification strain, $\varepsilon_{d}$, and $(b)$ the energy absorbed per unit volume, $W$, with the relative density, $\rho^{*}$, of the Alporas foam tested in compression with and without constraint.

that the scheme we have used to evaluate $\varepsilon_{d}$ (Figure 3(a)) should in fact yield higher values (by $\sim 5 \mathrm{pct}$ ) of $\varepsilon_{d}$ for the constrained case (as a horizontal line will intersect with the densification line at lower strains). This implies that under constraint, the onset of foam densification occurs relatively earlier.

The energy absorbed by the foam per unit volume, $W$, is the area under stress strain curve up to densification and is estimated from the compression stress-strain data using

$$
W=\int_{0}^{\varepsilon_{d}} \sigma(\varepsilon) d \varepsilon
$$

Figure 6(b) shows the variation of $W$ with $\rho^{*}$, which reveals that for all densities, $W$ for the constrained samples is $\sim 20$ pct higher than that by the unconstrained samples because of strain hardening.

\section{IMPLICATIONS}

Results presented in Section III suggest that the application of a lateral constraint has a significant influence on the plastic stress-strain response of the closed-cell Al foams. In particular, marked strain hardening is seen in the specimens tested with lateral constraint. From the applications point-of-view, this observation will have the following possible implications to the design of foam-filled components.

\section{A. Energy Absorption Efficiency}

Ideal foams are those that exhibit a constant plateau stress in compression. ${ }^{[1]}$ In reality, however, different aluminum foams exhibit marginal hardening even in the absence of a constraint. Of these, it has been observed that the compressive stress-strain response of lowdensity Alporas foams deviates the least from the Gibson-Ashby predictions. ${ }^{[1]}$ Kenesei et al. ${ }^{[26]}$ show that Alporas foams display nominal strain hardening and attribute it to the structural variability within the foam such as the variability in the cell size and $\rho^{*}$. Such variability causes the weakest struts to deform first followed by the elastic loading of the sample until the second weakest strut fails and so on. Such a collapse of progressively stronger struts has been proposed to lead to the observed macroscopic hardening. ${ }^{[26]}$

In addition to a constant plateau stress, ideal energy absorbers require, both for crash protection and blast amelioration applications, a long plateau regime. Material selection for applications such as packaging is made such that the plateau stress is always below the stress required or the deceleration caused by the foam is such that the effective velocity of the impact is lower than the limiting value for causing damage or injury to the protected object. ${ }^{[27]}$ The deviation from the ideal foam's response can be gaged by examining the energy absorption efficiency, $\eta$, defined as ${ }^{[27]}$

$$
\eta(\varepsilon)=\frac{\int_{0}^{\varepsilon} \sigma(\varepsilon) d \varepsilon}{\sigma_{\max }(\varepsilon) \varepsilon}
$$

where $\sigma_{\max }(\varepsilon)$ is the maximum stress experienced by the foam up to the strain $\varepsilon$. Note that for an ideal foam, $\eta=1$, whereas it is $=0.5$ for elastic-brittle solids. For other real materials, $\eta$ is a function of the strain by definition. In metallic foams, $\eta$ reaches a value of $\sim 90$ pct within the first 10 pct $\varepsilon$ and remains constant up to a strain of $\sim 60$ pct. This is the feature that makes these materials attractive candidates for impact energy absorption. ${ }^{[27]}$ The variation of $\eta$ with $\varepsilon$, for Alporas tested with and without constraint, is shown in Figure 7(a). As seen, $\eta$ reaches a maximum of $\sim 80$ pct in the constrained case as compared to $\sim 90 \mathrm{pct}$ in the unconstrained deformation. This is because of the strain hardening under constraint, which increases $\sigma_{\max }(\varepsilon)$ more rapidly than the energy absorbed up to that strain (the numerator in Eq. [7]). Note also that $\eta$ drops markedly after $\sim 50$ pet strain in the unconstrained case, whereas it is gradual in the case of the constrained samples. 
Ignoring the elastic part (which is reasonable because the plastic strains are significantly large and dominate the energy absorption) and assuming linear hardening, $\eta$ at $\varepsilon_{d}$ can be written as

$$
\left.\eta\right|_{\varepsilon=\varepsilon_{d}}=\frac{0.5\left(\frac{d \sigma}{d \varepsilon}\right) \varepsilon_{d}+\sigma_{p}}{\left(\frac{d \sigma}{d \varepsilon}\right) \varepsilon_{d}+\sigma_{p}}
$$

The preceding equation implies that for a given $\varepsilon_{d}, \eta$ depends on the relative value of $d \sigma / d \varepsilon$ with respect to $\sigma_{p}$. To illustrate this, variation of $\eta$ is plotted against $(d \sigma / d \varepsilon)$ normalized with $\sigma_{p}$ in Figure 7(b) for three different values of $\varepsilon_{d}$. It is seen that high hardening rates lead the foam's energy absorption efficiency farther away from the ideal foam behavior. At a typical $\varepsilon_{d}$ of 60 pct, the knockdown in $\eta$ for the case where $(d \sigma / d \varepsilon)=\sigma_{p}$ is $\sim 10$ pet, which is significant.

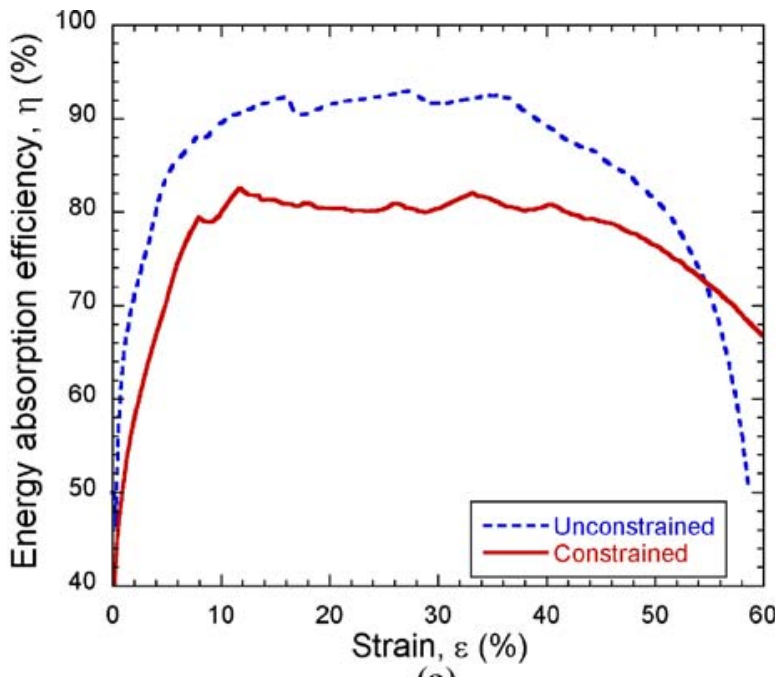

(a)

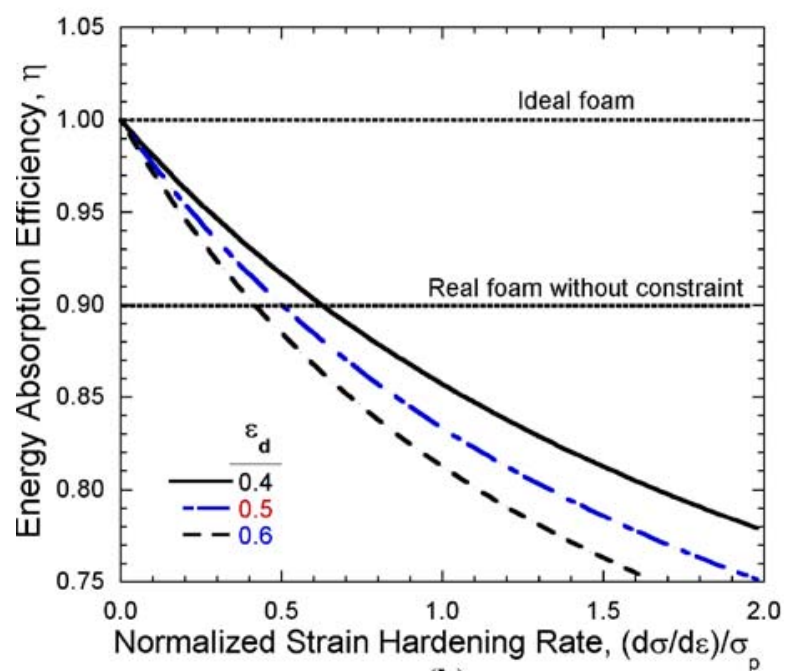

(b)

Fig. 7-Energy absorption efficiency, $\eta$, plotted as a function of $(a)$ the strain compressive strain, $\varepsilon$, for the Alporas foam tested in compression with and without constraint, and $(b)$ the strain-hardening rate, $d \sigma / d \varepsilon$, normalized with the plastic strength, $\sigma_{p}$.

\section{B. Strain Accumulation during Compression- Compression Fatigue Loading}

Another important consequence of strain hardening is where the foam-filled parts are subjected to cyclic loading and hence fatigue becomes an important design parameter. Prior work by Banhart et al., ${ }^{[28]}$ Sugimura et al., ${ }^{[29]}$ and Harte et al. ${ }^{[16]}$ shows that compressioncompression fatigue in metallic foams is characterized by progressive plastic strain accumulation. Further, Sugimura et al. divide accumulated plastic strain, $\varepsilon_{a}$, vs number of fatigue cycles, $N$, curves into three regimes, which follow the elastic deformation that occurs in the first cycle itself. The first regime follows a small strain that typically occurs over the first couple of decades of $N$. Following this stage I deformation, many cycles elapse with no further or minimal strain accumulation. This incubation period is referred to as stage II, which is followed by a rapid strain accumulation in stage III. This last stage continues until $\varepsilon_{d}$ is reached. In a sense, stage III deformation under fatigue is similar to that seen in unconstrained quasi-static loading of the foam. Therefore, the strain hardening seen with constraint is likely to affect the stage III deformation.

To examine this possibility further, constant stress amplitude compression-compression fatigue experiments were conducted. All of the experimental conditions were similar to those used for quasi-static loading. A frequency of $10 \mathrm{~Hz}$ (sine wave form) and load ratio (ratio of the minimum to the maximum compressive stress of the fatigue cycle) was maintained at 0.1 . The ratio of maximum compressive stress of the fatigue cycle, $\sigma_{\max }$, to the $\sigma_{p}$ (estimated for a given specimen's $\rho^{*}$ using Figure 4(a)) was maintained at 0.9. Representative $\varepsilon_{a} v s N$ plots obtained with and without constraint for $\left(\sigma_{\max } / \sigma_{p}\right)=0.9$ are shown in Figure 8. Here, the nominal $\rho^{*}$ for both specimens at the start of testing is

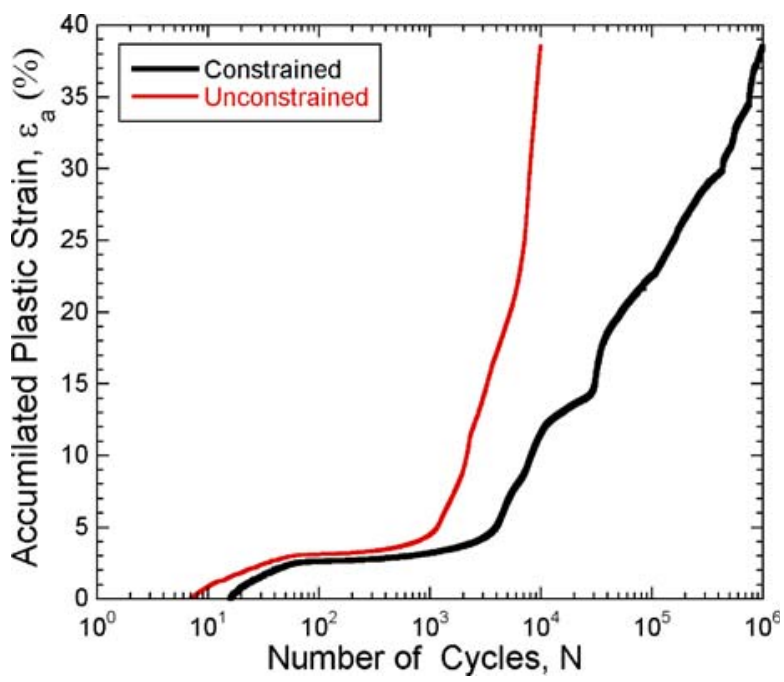

Fig. 8-Accumulated plastic strain, $\varepsilon_{a}$, as a function of number of fatigue cycles, $N$, illustrating the effect of constraint on the fatigue behavior of Alporas. Both the samples (with nearly identical relative densities, $\left.\rho^{*}\right)$ were tested such that the maximum stress of the fatigue cycle, $\sigma_{\max }$, corresponds to 90 pct of the plastic strength, $\sigma_{p}$, that was estimated using Fig. 4(a). 
nearly identical. As seen, at the end of stage I, $\varepsilon_{a}$ is similar $(\sim 3.5 \mathrm{pct})$ for both cases. Also, the onset of stage II occurs with about the same value of $N$. This is because the constraint does not exert any influence on the early stages of deformation. However, marked differences are seen in stage III. In the unconstrained sample, it is initiated sooner, followed by a rapid rise in $\varepsilon_{a}$. In contrast, the onset of stage III is delayed. More importantly, the rate of strain accumulation is much lower, and hence, the $\varepsilon_{a} v s N$ curves diverge significantly. This is because of the strain hardening in the constrained case. Although the applied value of $\left(\sigma_{\max } / \sigma_{p}\right)$ is maintained constant, the relatively rapid increase in the flow stress with strain in the laterally constrained samples reduces the effective $\left(\sigma_{\max } / \sigma_{p}\right)$ and, hence, it takes a considerably greater number of samples to cause the same amount of fatigue damage.

\section{CONCLUSIONS}

The experimental work reported in this article to examine the effect of lateral constraint on the mechanical behavior of a closed-cell Al foam leads to the following conclusions:

1. The plastic strength of Alporas is independent of the constraint and is sensitive only to the relative density.

2. The lateral constraint imparts significant strain hardening to the foam. While it slightly lowers the densification strain, the overall energy absorbed increases marginally.

3. The lateral constraint-induced strain hardening lowers the energy absorption efficiency of the foam by $\sim 10$ pct. It also reduces the strain accumulation rate in regime III of the compression-compression fatigue curves.

\section{ACKNOWLEDGMENTS}

We are grateful to S. Sasidhara and S. Gaonkar for their assistance with the work reported in this article. This project at IISc was funded by a grant from the Materials Panel of the Aeronautical Research and Development Board (AR\&DB), Ministry of Defence, Government of India.

\section{REFERENCES}

1. L.J. Gibson and M.F. Ashby: Cellular Solids-Structure and Properties, Cambridge University Press, Cambridge, United Kingdom, 1997.

2. E. Andrews, W. Sanders, and L.J. Gibson: Mater. Sci. Eng. A, 1999, vol. 270, pp. 113-24

3. Y. Sugimura, J. Meyer, M.Y. He, H. Bart-Smith, J. Grenestedt, and A.G. Evans: Acta Mater., 1997, vol. 45, pp. 5245-59.

4. O.B. Olurin, N.A. Fleck, and M.F. Ashby: Mater. Sci. Eng. A, 2000, vol. 291, pp. 136-46.

5. B. Kriszt, B. Foroughi, K. Faure, and H.P. Degischer: Mater. Sci. Technol., 2000, vol. 16, pp. 792-96.

6. C. Motz and R. Pippan: Acta Mater., 2001, vol. 49, pp. 2463-70.

7. S. Karthikeyan, M. Kolluri, and U. Ramamurty: Metall. Mater. Trans. A, DOI: 10.1007/s11661-007-9213-z.

8. T. Miyoshi, M. Itah, S. Akiyama, and A. Kitahara: Adv. Eng. Mater., 2000, vol. 2, pp. 179-83.

9. A. Paul and U. Ramamurty: Mater. Sci. Eng. A, 2000, vol. 281, pp. 1-7.

10. J. Banhart: Progr. Mater. Sci., 2001, vol. 46, pp. 559-632.

11. A.E. Simone and L.J. Gibson: Acta Mater., 1998, vol. 46, pp. $2139-50$.

12. M. Doyoyo and D. Mohr: Mech. Mater., 2006, vol. 38, pp. 32539.

13. S. Ramachandra, P. Sudheer Kumar, and U. Ramamurty: Scripta Mater., 2003, vol. 49, pp. 741-45.

14. P. Sudheer Kumar, S. Ramachandra, and U. Ramamurty: Mater. Sci. Eng. A, 2003, vol. 347, pp. 330-37.

15. U. Ramamurty and A. Paul: Acta Mater., 2004, vol. 52, pp. 869 76.

16. A.M. Harte, N.A. Fleck, and M.F. Ashby: Acta Mater., 1999, vol. 47, pp. 2511-24.

17. A.E. Simone and L.J. Gibson: Acta Mater., 1998, vol. 46, pp. $2139-50$.

18. A.G. Evans, J.W. Hutchinson, and M.F. Ashby: Progr. Mater. Sci., 1999, vol. 43, pp. 171-221.

19. A.E. Simone and L.J. Gibson: Acta Mater., 1998, vol. 46, pp. 3929-35.

20. M.F. Ashby, A.G. Evans, N.A. Fleck, L.J. Gibson, J.W. Hutchinson, and H.N.G. Wadley: Metal Foams: a Design Guide, Butterworth-Heineman, Oxford, United Kingdom, 2000.

21. V.S. Deshpande and N.A. Fleck: J. Mech. Phys. Sol., 2000, vol. 48, pp. $1253-83$.

22. G. Gioux, T.M. McCormach, and L.J. Gibson: Int. J. Mech. Sci., 2000, vol. 42, pp. 1097-1117.

23. R.E. Miller: Int. J. Mech. Sci., 2000, vol. 42, pp. 729-54.

24. J. Zhang, N. Kikuchi, V.C. Li, A.F. Yee, and G.S. Nusholtz: Int. J. Imp. Eng., 1998, vol. 21, pp. 369-86.

25. A.F. Bastawros, H. Bart-Smith, and A.G. Evans: J. Mech. Phys. Sol., 2000, vol. 48, pp. 301-22.

26. P. Kenesei, C. Kadar, Z. Rajkovits, and J. Lendvai: Scripta Mater., 2004, vol. 50, pp. 295-300.

27. J. Baumeister, J. Banhart, and M. Weber: Mater. Des., 1997, vol. 18 , pp. 217-20.

28. J. Banhart and W. Brinkers: J. Mater. Sci. Lett., 1999, vol. 18, pp. 617-19.

29. Y. Sugimura, A. Rabiei, A.G. Evans, A.M. Harte, and N.A. Fleck: Mater. Sci. Eng. A, 1999, vol. 269, pp. 38-48. 